\title{
EMPREENDEDORISMO E PRECARIZAÇÃO DO TRABALHO: O DESENVOLVIMENTO E A APLICAÇÃO DE UMA ESTRUTURA PARA ANÁLISE DE EMPREENDEDORAS NO ESTADO DE SÃO PAULO
}

DOI: $10.14211 / 41164$

Artigo recebido em: 28/07/2014. Artigo aprovado em: 17/11/2014.

Luís Henrique Rigato Vasconcellos - Fundação Getulio Vargas ${ }^{1}$ Denise Poiani Delboni - Fundação Getulio Vargas ${ }^{2}$

Resumo: O objetivo deste artigo é a análise e a exposição simultânea de dois temas: a natureza do empreendedorismo e a questão da precarização do trabalho relativa à figura do empreendedor. Assim, objetiva-se uma convergência na literatura sobre a definição e a caracterização do que se compreende por trabalho precário, associando-o aos chamados empreendedorismo por necessidade e empreendedorismo por oportunidade. $O$ estudo foi desenvolvido por meio da aplicação de uma pesquisa tipo survey descritiva envolvendo 110 empreendedoras no estado de São Paulo. Os resultados mostraram que o Índice Global de Precarização, a partir do modelo proposto, foi próximo de $60 \%$, não havendo diferenças significativas entre os tipos de empreendedoras.

Palavras-chave: Empreendedorismo feminino, trabalho precário, empreendedorismo por oportunidade, empreendedorismo por necessidade.

\section{ENTREPRENEURSHIP AND PRECARIOUSNESS OF WORK: DEVELOPMENT AND APPLICATION OF A FRAMEWORK FOR ANALYSIS OF WOMAN ENTREPRENEURS IN SAO PAULO STATE}

Abstract: The aim of this paper is the analysis of precarious work relating to the figure of the entrepreneur. For this purpose, it was attempted to define and characterize what is meant by precarious work, associating it with the so-called necessity entrepreneurship and entrepreneurship by opportunity. The study was developed through the application of a descriptive survey type research involving 110 entrepreneurs in the state of São Paulo. The results showed that the Global Insecurity Index, from the proposed model, was close to $60 \%$, with no significant differences between the types of entrepreneurs.

Keywords: Female entrepreneurship, precarious work, entrepreneurship by opportunity, entrepreneurship by necessity.

\footnotetext{
${ }^{1}$ E.mail: luis.vasconcellos@fgv.br - Endereço: Av. 9 de Julho, 2029, Bela Vista, São Paulo - SP, CEP: 01313-902.

2 E.mail: denise.delboni@fgv.br
}

VASCONCELLOS, L. H. R.; DELBONI, D. P. Empreendedorismo e precarização do trabalho: o desenvolvimento e a aplicação de uma estrutura para análise de empresárias no estado de São Paulo. Revista de Empreendedorismo e Gestão de Pequenas Empresas, v. 4, n. 1, 2015. 
Introdução

Ao longo de toda a história, os trabalhadores parecem partilhar do firme propósito de que ter o seu próprio negócio os tornaria mais independentes, com maior autonomia para a tomada de decisões e, ainda, com maior liberdade para usufruírem da vida. No Brasil, sobretudo nas últimas décadas, muitas pessoas têm migrado para o mundo empresarial guiadas, muitas vezes, pela busca de melhor qualidade de vida (LINDO et al., 2007; MONTALI, 2004).

Assim, no período de apenas um ano, de 2012 para 2013, houve um aumento de seis pontos percentuais no crescimento do número de empreendimentos iniciais na região sudeste do Brasil. Foi analisada a população com faixa etária compreendida entre 18 e 64 anos de idade. Destes, 32,3\% (próximo dos 40 milhões de pessoas) trabalham com negócio próprio (GEM, 2013, p. 04).

Independentemente da razão que os leva a abrir seu próprio negócio, parece notória a dificuldade para que prosperem, bem como distantes a tão almejada independência financeira e a maior autonomia na rotina de trabalho. Em outras palavras, o fato de um grande número de empregados desejar abrir seu próprio negócio pode não assegurar o acesso a rotinas isentas de precariedade verificada em tantos postos de trabalho no mundo atual.

Nesta linha, por meio do presente trabalho, indaga-se em que medida a precarização do trabalho, fenômeno que afeta grande parte da população de empregados ao redor do mundo, poderia afetar também as mulheres empreendedoras, sobretudo em empresas de micro e pequeno portes, muitas destas ainda em início de atividades.

Para a investigação deste problema, foram consideradas apenas empreendedoras mulheres, sobretudo por duas razões: tratam-se do grupo que mais procura qualidade de vida no trabalho, buscando conciliar o trabalho e a vida pessoal, além do fato de já representarem hoje, no Brasil, a maioria dos empreendedores iniciais, num total de $51,2 \%$ de mulheres contra $48,8 \%$ de homens empreendedores (GEM, 2013, p. 09).

VASCONCELLOS, L. H. R.; DELBONI, D. P. Empreendedorismo e precarização do trabalho: o desenvolvimento e a aplicação de uma estrutura para análise de empresárias no estado de São Paulo. Revista de Empreendedorismo e Gestão de Pequenas Empresas, v. 4, n. 1, 2015. 
A segunda razão pela escolha das mulheres empreendedoras é a facilidade de acesso a elas. Os autores deste trabalho foram professores das empreendedoras do programa "10 mil mulheres", entre 2011 e 2014, destinado à capacitação de empreendedoras na cidade de São Paulo ${ }^{3}$. Assim eles possuíam um contato mais estreito com o público pesquisado, fato que facilitou a execução desta pesquisa.

\section{Empreendedorismo por necessidade e por oportunidade}

O processo de abertura econômica e de inserção do Brasil no mercado globalizado, na década de 1990, desencadeou uma reestruturação produtiva forçada para enfrentar a forte concorrência externa, que teve por consequências: fechamento de fábricas, terceirização, subcontratação, renovação tecnológica, reorganização de processos produtivos e o enxugamento do quadro de empregados (COSTA, 2003).

A partir de então, muitos trabalhadores, especialmente aqueles não absorvidos pelo setor de serviços ou comércio, viram-se obrigados a procurar alternativas de trabalho para suas subsistências, em condições adversas, passando a atuar como temporários, autônomos ou sendo deslocados para a informalidade, onde as condições eram ainda mais precárias (ANTUNES, 2002).

Em um quadro de relações de trabalho permeadas de insegurança e baixos salários, surgiram os empreendedores por necessidade, definidos como indivíduos que criam um negócio próprio, motivados pela falta de alternativa satisfatória de ocupação e renda (SEBRAE, 2005).

No Brasil, a necessidade foi, até alguns anos atrás, o principal fator de motivação para as mulheres iniciarem seu próprio negócio. Enquanto $38 \%$ dos homens empreendiam por necessidade, esta proporção aumentava para $63 \%$ no caso das mulheres, há apenas alguns anos. Esses dados do IBGE/PNAD (2006) corroboravam a indicação sobre o fato de que as mulheres buscavam alternativas de

\footnotetext{
${ }^{3} \mathrm{O}$ programa "10 mil mulheres" teve início no Brasil, em 2008, fruto da parceria entre a Fundação Getúlio Vargas/SP e Fundação Goldman Sachs, numa iniciativa filantrópica global com o objetivo de promover educação em administração e gestão de negócios a mulheres empreendedoras e já formou 380 alunas em São Paulo. Disponível em http://www.10000mulheres.com.br/programa
}

VASCONCELLOS, L. H. R.; DELBONI, D. P. Empreendedorismo e precarização do trabalho: o desenvolvimento e a aplicação de uma estrutura para análise de empresárias no estado de São Paulo. Revista de Empreendedorismo e Gestão de Pequenas Empresas, v. 4, n. 1, 2015. 
empreendimento para complementar a renda familiar ou, ainda, porque nos últimos anos elas vinham assumindo cada vez mais o sustento do lar como chefes da família.

Segundo o Global Entrepreneurship Monitor (GEM, 2013), entre 2001 e 2005, o número de empreendedores por necessidade no Brasil, incluindo homens e mulheres, evoluiu de $40 \%$ para $47 \%$, atingindo o ápice de 55\% em 2002. De acordo com o SEBRAE (2004), a grave situação de desemprego e a precariedade dos serviços de assistência e bem-estar social, explicavam o fato do país registrar esta taxa significativa, com um grande contingente alijado do mercado de trabalho, sendo forçado a procurar a criação de empreendimentos como alternativa de sobrevivência.

Dentre os motivos pelos quais as microempresas informais foram abertas, lá estavam, desde 2003, a dificuldade de encontrar um emprego $(31,1 \%)$ e a necessidade de complementação de renda familiar (17,6\%). Mas, curiosamente, do lado dos empregadores do sexo masculino, o motivo principal para a abertura do negócio foi a busca por independência (24,3\%), enquanto o fato de não encontrarem emprego ficou em segundo lugar (16\%) (SEBRAE, 2005; COLODETI, LEITE, 2015).

Não por outra razão, Colbari (2007) destaca a alta taxa de empreendedorismo nos países mais pobres, uma vez que a taxa está associada a fatores demográficos, econômicos e dificuldade de inserção social, sobretudo entre as pessoas com difícil acesso à educação. Situação esta, aliás, que se agrava ainda mais no caso de trabalho assalariado informal (PAMPLONA, 2001), normalmente mal remunerado e, portanto, incapaz de promover a continuidade nos estudos e qualificação dos empregados.

Entretanto, de acordo com os dados mais recentes do GEM (2013) sobre empreendimentos iniciais, o empreendedorismo por necessidade parece ter cedido lugar ao empreendedorismo por oportunidade, passando este último a representar $71,3 \%$ dos novos negócios que surgem no país, índice alavancado justamente pela região sudeste do Brasil (GEM, 2013, p. 05).

Ao contrário do empreendedorismo por necessidade, o empreendedorismo por oportunidade é definido como o conjunto de indivíduos motivados pela

VASCONCELLOS, L. H. R.; DELBONI, D. P. Empreendedorismo e precarização do trabalho: o desenvolvimento e a aplicação de uma estrutura para análise de empresárias no estado de São Paulo. Revista de Empreendedorismo e Gestão de Pequenas Empresas, v. 4, n. 1, 2015. 
percepção de um nicho de mercado potencial, por um sentimento de responsabilidade pela geração de emprego e desenvolvimento industrial no país, e que desejam investir em um negócio próprio (SEBRAE, 2005, 2006).

Os empreendedores por oportunidade buscam, na maioria das vezes, benefícios atribuídos ao trabalho por conta própria, como: maior independência; liberdade para tomar decisões sobre os negócios e prestar contas apenas para si mesmo; oportunidades de enfrentar desafios; fuga da posição de subordinado; satisfação e orgulho; e possibilidade de dedicar mais tempo à família ou de abandonar a rotina (SOUZA, 2005).

A distribuição dos novos empreendimentos por setor de atividade entre 2002 e 2005 revela que os serviços orientados ao consumidor são os mais procurados pelos empreendedores iniciais, porém, a proporção de empreendedores que conseguem se estabelecer neste tipo de atividade é significativamente menor. Isso sugere que, mesmo com as mudanças, muitos negócios ainda são abertos sem grandes diferenciais ou inovações e têm considerável dificuldade de obter sucesso no mercado, sendo possível inferir que tais empreendimentos são altamente procurados devido à baixa necessidade de investimento inicial e relativa facilidade de acesso (GEM, 2006), o que poderia influenciar na precariedade de seu desempenho.

\section{Trabalho precário e empreendedorismo feminino no Brasil}

Para a caracterização do conceito de trabalho precário associado à rotina de empreendedores, optou-se pela aplicação dos conceitos de Cattani e Holzmann (2006), Gomeza (1999) e Antunes (2007), enfatizando, sobretudo, os aspectos voltados para a ausência ou redução de direitos e garantias do trabalho e para a qualidade de vida no exercício da atividade. Para esses autores, a precarização do trabalho se revela como uma sequência de perdas, como redução da perspectiva profissional (remuneração insatisfatória, contratos temporários incertos, jornadas de trabalho extensas) e supressão de direitos (descanso remunerado, férias, licenças de saúde, aposentadoria e regulação dos salários, entre outros).

VASCONCELLOS, L. H. R.; DELBONI, D. P. Empreendedorismo e precarização do trabalho: o desenvolvimento e a aplicação de uma estrutura para análise de empresárias no estado de São Paulo. Revista de Empreendedorismo e Gestão de Pequenas Empresas, v. 4, n. 1, 2015. 
O conceito de precariedade no trabalho é a antítese do que seja considerado trabalho decente, de acordo com o que prevê a OIT (2006) ao se referir aos trabalhos produtivos, adequadamente remunerados, exercidos em condições de liberdade, equidade, segurança e capazes de garantir uma vida digna. Trata-se, portanto, de um trabalho decente, daquele capaz de satisfazer às necessidades pessoais e familiares de alimentação, educação, moradia, saúde e segurança, ao mesmo tempo em que assegura proteção social nos impedimentos de seu exercício (desemprego, doença, acidentes, entre outros), renda ao chegar à época da aposentadoria e respeito aos direitos fundamentais dos trabalhadores.

No tocante à garantia de direitos trabalhistas, parece nítida a sua perda entre os empreendedores, sobretudo no caso de empresas em início de atividades: o fato de estar desvinculado de qualquer emprego faz com que recaia sobre o próprio empreendedor a responsabilidade pelo recolhimento de verbas como seguro de vida e a contribuição de INSS (Instituto Nacional de Seguridade Social), o que muitas vezes se torna impossível diante da ausência de recursos financeiros naquelas circunstâncias. Holzman (2006) indica, por exemplo, a partir de dados do IBGE (Instituto Brasileiro de Geografia e Estatística), que 78,3\% dos empreendedores por necessidade não contribuem para a previdência social.

De um modo geral, é possível afirmar que a precarização do trabalho está diretamente associada à eliminação de direitos sociais agregados aos contratos de trabalho que justamente constituíam a "cidadania salarial" ou o welfare state dos anos 50 nos países capitalistas centrais. E, ainda, pensar em precariedade do trabalho esbarra, invariavelmente, na ideia de que por meio do trabalho não se conseguiria conciliar objetivos pessoais com outros de ordem econômica, sem qualquer prejuízo aos direitos no trabalho e relativos a questões de saúde e sobrevivência econômica do trabalhador (HIRATA; PRETECEILLE, 2002).

Entretanto, de modo paradoxal, a própria precariedade do trabalho aliada ao déficit de lugares ocupáveis na estrutura social (mercado de trabalho insuficiente aliado ao crescente número de pessoas desqualificadas para seu exercício) seriam os grandes fatores responsáveis pela insegurança no emprego (CASTEL, 1998), como também fatores responsáveis pela conjectura de muitos trabalhadores sobre a

VASCONCELLOS, L. H. R.; DELBONI, D. P. Empreendedorismo e precarização do trabalho: o desenvolvimento e a aplicação de uma estrutura para análise de empresárias no estado de São Paulo. Revista de Empreendedorismo e Gestão de Pequenas Empresas, v. 4, n. 1, 2015. 
possibilidade de abertura do negócio próprio, migrando da condição de empregados para a de empreendedores.

Holzman (2006) entende que justamente o empreendedor por necessidade é aquele que passa a empreender por conta da ausência total de possibilidade de absorção no mercado de trabalho, fazendo com que, mesmo como empreendedor, se distancie bastante do trabalho decente. Assim, em um primeiro momento, a mudança de condição de trabalho que parecia apontar para uma situação de autonomia e melhor qualidade de vida, parece provocar a repetição, não raras vezes, de alguns padrões de precariedade também na rotina dos empreendedores, particularmente no início de suas atividades.

Aliás, o fato de tornar-se um empreendedor muitas vezes confunde-se com a própria precarização, uma vez que na perspectiva do autoemprego, o dono de um novo e pequeno negócio não usufrui de nenhum dos diretos assegurados para o trabalhador assalariado, como as férias, remuneração nos períodos de parada de trabalho por enfermidade, descanso remunerado, seguro desemprego, aposentadoria, etc. (GALEAZZI, 2002). E assim, sob a ótica da "autonomia", proliferam cooperativas, microempresas e empresas de pequeno porte, associações de trabalhadores, empreendimentos familiares, trabalho domiciliar, prestações de serviços, enfim, modalidades de trabalho que se inscrevem na categoria de conta própria (TAVARES, 2004).

No âmbito nacional, como visto anteriormente, as mulheres criam e lideram cada vez mais empreendimentos em diversos setores produtivos, justamente elas, que utilizam o discurso do maior controle sobre o tempo, da conciliação dos afazeres profissionais com a família, enfim, de melhor qualidade de vida (BARONI, 2008). Os papéis e tarefas socialmente atribuídos às mulheres em relação à sua família parecem traduzir-se em um obstáculo significativo para o acesso, permanência e prosperidade de seu empreendimento. Esses papéis e tarefas são determinantes de suas condições de inserção no mercado de trabalho, seja como empregada ou como empreendedora (BULGACOV et al., 2010).

No Brasil, os dados da Pesquisa GEM (2013) revelam que no período entre 2001 e 2008 houve uma tendência de aumento da participação da mulher na

VASCONCELLOS, L. H. R.; DELBONI, D. P. Empreendedorismo e precarização do trabalho: o desenvolvimento e a aplicação de uma estrutura para análise de empresárias no estado de São Paulo. Revista de Empreendedorismo e Gestão de Pequenas Empresas, v. 4, n. 1, 2015. 
atividade empreendedora, o que pode ser considerado uma característica do empreendedorismo de países pobres ou em desenvolvimento. Por exemplo, entre os sete países com maior taxa de empreendedorismo feminino destacam-se, por ordem decrescente: Peru (26\%), Tailândia (26\%), Colômbia (19\%), Venezuela (17\%), República Dominicana (14,5\%), China (13,4\%) e Brasil (12,7\%), justamente os países com maiores níveis de desigualdade.

No caso brasileiro, entretanto, há o indicador aumento da escolaridade entre as mulheres capazes de justificar suas inserções na atividade empreendedora. Contudo, não se pode afirmar de pronto a relação direta entre baixa renda e trabalho precário entre as empreendedoras (VALE, 2010).

De imediato, a dificuldade financeira para a contratação de empregados e expansão do negócio faz com que os micros e pequenos empreendimentos, em sua grande maioria, empreguem pouco. A maior parte dos empreendimentos iniciais não possui empregados (66,1\%), 17,8\% têm apenas um empregado e apenas 8,9\% têm dois ou mais empregados. Estes dados parecem indicar um excesso de tarefas e responsabilidades sobre a pessoa do empreendedor, inclusive de forma mais acentuada no empreendedorismo por necessidade, situação em que $76,6 \%$ dos pequenos negócios não têm empregados (contra 61,2\% de empresas sem quaisquer empregados, no caso de empreendedorismo por oportunidade) (GEM, 2013, p. 13).

Sob a ótica da jornada de trabalho, conforme sinalizam Lindo et al. (2007), também não parece ser diferente. A empreendedora, apesar de lograr liberdade para organizar seu dia, trabalha mais ao longo da jornada diária de trabalho. Enquanto um emprego tradicional demanda 8 horas diárias, conforme a legislação brasileira, a empreendedora, no Brasil, labora em média 13 horas diárias.

Também quanto ao faturamento, embora conscientes das dificuldades iniciais, mas confiantes de uma rentabilidade maior ao longo do tempo na condição de empreendedoras, é fato que $67,1 \%$ dos novos empreendimentos têm faturamento anual na faixa de $R \$ 60$ mil, sendo que uma fatia expressiva declara sequer ter faturamento (GEM, 2013, p. 14). Isso implica diretamente na questão da sobrevivência das empreendedoras, podendo afetar consideravelmente seu padrão

VASCONCELLOS, L. H. R.; DELBONI, D. P. Empreendedorismo e precarização do trabalho: o desenvolvimento e a aplicação de uma estrutura para análise de empresárias no estado de São Paulo. Revista de Empreendedorismo e Gestão de Pequenas Empresas, v. 4, n. 1, 2015. 
de vida e o de seus familiares. Essa situação agrava-se ainda mais diante das estatísticas no Brasil: atualmente, cerca de 40\% das famílias é chefiada por mulheres (contra 28\%, no ano de 2002) (IBGE, 2013, p. 73).

Em decorrência da necessária economia para o início das atividades de uma nova empresa, Antunes (2007) ressalta a questão da precariedade associada à perda de remuneração, o que pode comprometer os gastos com itens básicos de subsistência. De acordo com o Dieese (2014), o salário mínimo necessário para o sustento de uma família que vive em grandes capitais, em abril de 2014, aproximase dos $\mathrm{R} \$ 3.000,00$ mensais, valor que muitas vezes não é percebido pelos micros e pequenos empreendedores após o desconto de todos os custos e despesas gerados por seu negócio.

No quadro 1 a seguir é elaborada uma síntese dos fatores considerados para a caracterização de um trabalho precário, com a indicação de autores e fontes para sua sustentação teórica, bem como uma breve justificativa adotada pelos pesquisadores deste estudo.

VASCONCELLOS, L. H. R.; DELBONI, D. P. Empreendedorismo e precarização do trabalho: o desenvolvimento e a aplicação de uma estrutura para análise de empresárias no estado de São Paulo. Revista de Empreendedorismo e Gestão de Pequenas Empresas, v. 4, n. 1, 2015. 


\begin{tabular}{|c|c|c|}
\hline $\begin{array}{c}\text { FATORES PARA } \\
\text { CARACTERIZAÇÃO DE } \\
\text { TRABALHO PRECÁRIO }\end{array}$ & $\begin{array}{l}\text { AUTORES E FONTES } \\
\text { PARA SUSTENTAÇÃO } \\
\text { TEÓRICA }\end{array}$ & $\begin{array}{c}\text { JUSTIFICATIVA ADOTADA PELOS } \\
\text { AUTORES (TRABALHO PRECÁRIO X } \\
\text { EMPREENDEDORISMO) }\end{array}$ \\
\hline $\begin{array}{l}\text { a) Jornada de trabalho } \\
\text { superior a } 44 \text { horas } \\
\text { semanais; }\end{array}$ & $\begin{array}{l}\text { Cattani e Holzmann } \\
\text { (2006); Lindo et al. } \\
\text { (2007); Baroni (2008); } \\
\text { Antunes (2008). }\end{array}$ & $\begin{array}{l}\text { A jornada de trabalho de um } \\
\text { empreendedor é usualmente superior } \\
\text { de um assalariado regido pela CLT. }\end{array}$ \\
\hline $\begin{array}{l}\text { b) Trabalho frequente } \\
\text { aos finais de } \\
\text { semana; }\end{array}$ & $\begin{array}{l}\text { Cattani e Holzmann } \\
\text { (2006); Lindo et al. } \\
\text { (2007). }\end{array}$ & $\begin{array}{l}\text { Muitas vezes, pela natureza do } \\
\text { negócio, é praxe para o empreendedor } \\
\text { trabalhar aos finais de semana e } \\
\text { feriados. }\end{array}$ \\
\hline $\begin{array}{l}\text { c) Rendimento médio } \\
\text { mensal inferior ao } \\
\text { mínimo necessário } \\
\text { para o sustento de } \\
\text { uma família; }\end{array}$ & $\begin{array}{l}\text { Dieese (2014); IBGE } \\
\text { (2013); GEM (2013); } \\
\text { Leme (1998); Antunes } \\
\text { (2007). }\end{array}$ & $\begin{array}{l}\text { Espera-se que o rendimento médio de } \\
\text { um empresário, com nível universitário } \\
\text { e mais de cinco anos de atuação seja } \\
\text { maior que } R \$ 4.500,00 \text { isto é, } \\
\text { equivalente a } 1,5 \text { salário mínimo } \\
\text { necessário para o sustento de uma } \\
\text { família nas grandes capitais. }\end{array}$ \\
\hline $\begin{array}{l}\text { d) Duas semanas ou } \\
\text { menos de férias no } \\
\text { último ano; }\end{array}$ & $\begin{array}{l}\text { Galeazzi (2002); } \\
\text { Tavares (2004). }\end{array}$ & $\begin{array}{l}\text { A falta de tempo ou de recursos } \\
\text { suficientes impede que os empresários } \\
\text { consigam usufruir tempo de férias } \\
\text { superior a duas semanas por ano. }\end{array}$ \\
\hline $\begin{array}{l}\text { e) Execução de tarefas } \\
\text { predominantemente } \\
\text { operacionais no dia } \\
\text { a dia de trabalho; }\end{array}$ & $\begin{array}{l}\text { Hirata e Preteceille } \\
\text { (2002); Tavares (2004); } \\
\text { Cattani e Holzmann } \\
\text { (2006). }\end{array}$ & $\begin{array}{l}\text { As atividades do dia a dia do } \\
\text { empreendedor podem envolver grande } \\
\text { número de tarefas operacionais, } \\
\text { tornando o trabalho precário. }\end{array}$ \\
\hline $\begin{array}{l}\text { f) Sentimento } \\
\text { frequente de } \\
\text { depressão e } \\
\text { ansiedade pela } \\
\text { natureza do } \\
\text { trabalho; }\end{array}$ & $\begin{array}{l}\text { Vale (2010); Galeazzi } \\
\text { (2002); Vieira (2013). }\end{array}$ & $\begin{array}{l}\text { Pode-se associar a natureza de um } \\
\text { trabalho precário a fontes individuais } \\
\text { de ansiedade e depressão, oriundas } \\
\text { pela sobrecarga de responsabilidades. }\end{array}$ \\
\hline $\begin{array}{l}\text { g) Necessidade de } \\
\text { uma fonte alternativa } \\
\text { de renda para a } \\
\text { subsistência; }\end{array}$ & $\begin{array}{l}\text { GEM (2013); Castel } \\
\text { (1998); Kremer (2005). }\end{array}$ & $\begin{array}{l}\text { Por não conseguir um rendimento } \\
\text { adequado com o empreendimento, há } \\
\text { a necessidade de outra fonte, como } \\
\text { outro trabalho formal ou auxílio de } \\
\text { familiares. }\end{array}$ \\
\hline $\begin{array}{l}\text { h) Ausência de um } \\
\text { Plano de } \\
\text { Previdência Privada } \\
\text { ou contribuição para } \\
\text { o INSS. }\end{array}$ & $\begin{array}{l}\text { Gomez (1999); Holzman } \\
\text { (2006). }\end{array}$ & $\begin{array}{l}\text { De forma geral não há a preocupação } \\
\text { em garantir um plano de } \\
\text { aposentadoria que seja equivalente ao } \\
\text { rendimento médio pelo } \\
\text { empreendimento. }\end{array}$ \\
\hline
\end{tabular}

QUADRO 1 - Fatores para a caracterização de Trabalho Precário

Fonte: Elaborado pelos autores (2015)

A figura 1 a seguir apresenta os fatores considerados para a representação do trabalho precário que serão utilizados para a pesquisa neste artigo para o trabalho dos empreendedores: a) jornada de trabalho superior a 44 horas semanais; b) trabalho frequente aos finais de semana; c) rendimento médio mensal inferior a

VASCONCELLOS, L. H. R.; DELBONI, D. P. Empreendedorismo e precarização do trabalho: o desenvolvimento e a aplicação de uma estrutura para análise de empresárias no estado de São Paulo. Revista de Empreendedorismo e Gestão de Pequenas Empresas, v. 4, n. 1, 2015. 
1,5 salário mínimo (DIEESE, 2014); d) férias inferiores a duas semanas no último ano; e) execução de tarefas predominantemente operacionais na rotina empresarial; f) sentimento frequente de depressão e/ou ansiedade em decorrência do trabalho; $g$ ) necessidade de uma fonte alternativa de renda para subsistência; e h) ausência de um plano de previdência privada ou recolhimento de INSS.

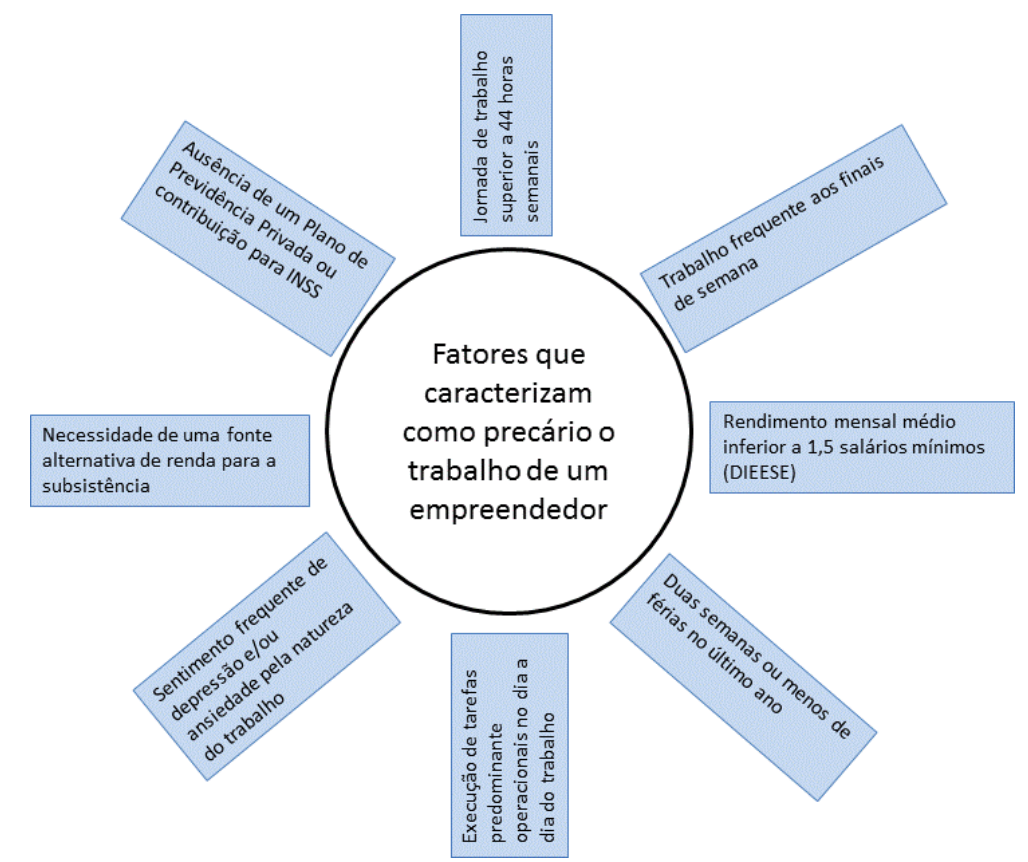

FIGURA 1 - Fatores que caracterizam como trabalho precário a rotina de um empreendedor Fonte: Elaborado pelos autores (2015)

\section{Procedimentos metodológicos}

Este artigo busca uma melhor compreensão sobre a possível relação entre o tema precarização do trabalho e o empreendedorismo feminino. Especificamente, o objetivo da pesquisa realizada é verificar se o trabalho de uma empreendedora pode ser caracterizado como precário, a partir da estrutura proposta e aplicada pelos autores deste texto. Para tanto, foi utilizado uma pesquisa do tipo survey, isto é, uma técnica de pesquisa para obtenção de dados ou informações sobre características, ações ou opiniões de determinado grupo de pessoas, indicado como representante de uma população alvo por meio de um instrumento, normalmente um questionário (FINK, 1995).

VASCONCELLOS, L. H. R.; DELBONI, D. P. Empreendedorismo e precarização do trabalho: o desenvolvimento e a aplicação de uma estrutura para análise de empresárias no estado de São Paulo. Revista de Empreendedorismo e Gestão de Pequenas Empresas, v. 4, n. 1, 2015. 
O tipo de survey deste artigo é o descritivo, pois procura descrever, a partir de uma amostra de empreendedoras, situações e opiniões acerca de questões relacionadas à precarização do trabalho para, em seguida, fazer comparações entre os resultados.

A partir do objetivo estabelecido para o presente trabalho, foram formuladas as seguintes questões de pesquisa:

- Q1: Que tipo de estrutura poderia ser empregado para a caracterização de um trabalho precário entre empreendedoras?

- Q2: É possível criar um índice capaz de medir diferentes níveis de precarização para diferentes tipos de empreendedoras?

- Q3: De um modo geral, o trabalho das empreendedoras pode ser caracterizado como precário?

- Q4: Os índices de precarização do trabalho podem ser diferentes quando comparadas às empreendedoras por oportunidade frente às empreendedoras por necessidade?

A partir do referencial teórico apresentado no quadro 1, considerando-se os fatores que caracterizam um trabalho precário também apresentados na figura 1, é possível a proposta de uma estrutura para medir a precarização do trabalho de uma dada amostra de empreendedoras, conforme figura 2 :

VASCONCELLOS, L. H. R.; DELBONI, D. P. Empreendedorismo e precarização do trabalho: o desenvolvimento e a aplicação de uma estrutura para análise de empresárias no estado de São Paulo. Revista de Empreendedorismo e Gestão de Pequenas Empresas, v. 4, n. 1, 2015. 


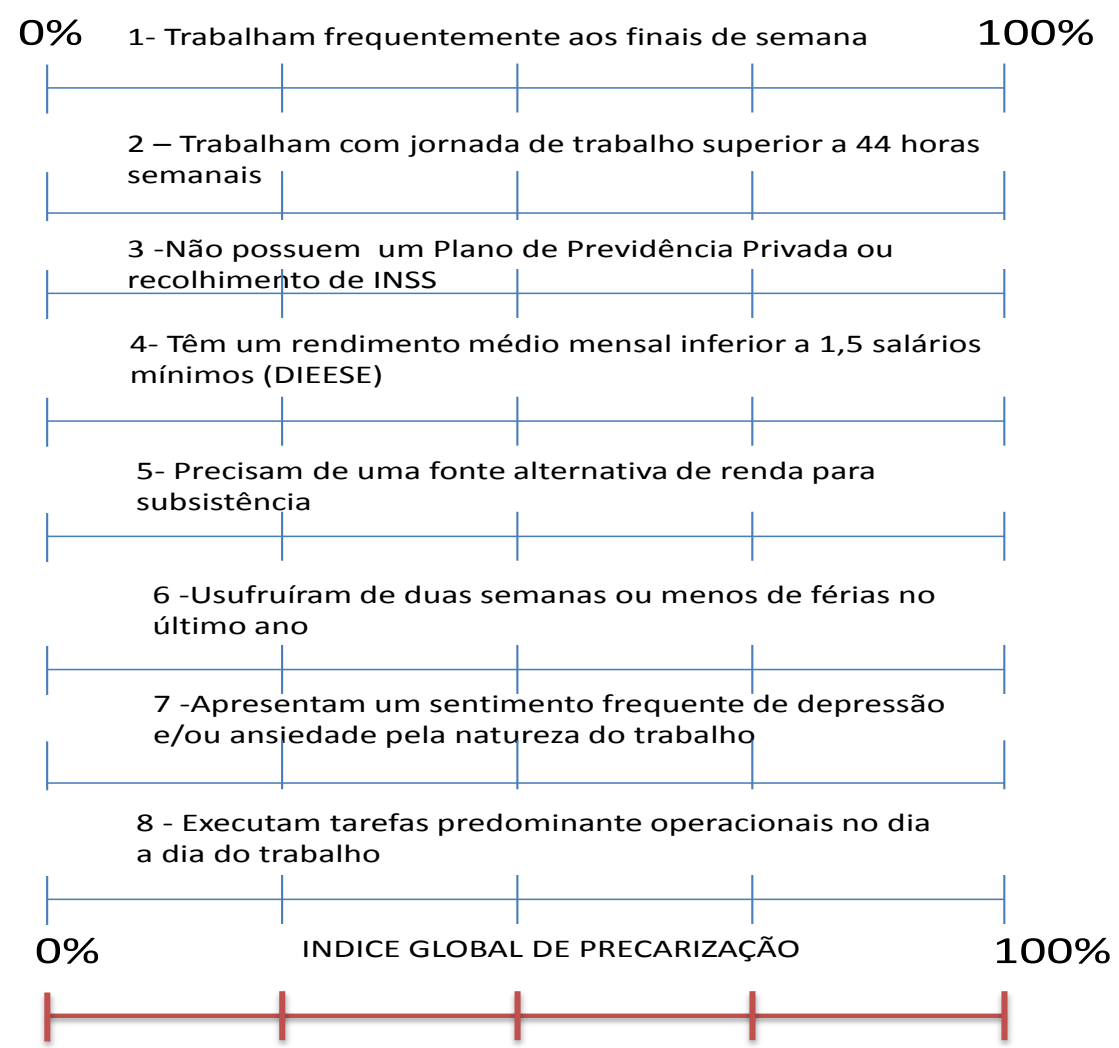

FIGURA 2 - Estrutura para medir a precarização do trabalho para empreendedores Fonte: Elaborado pelos autores (2015)

A ideia central da estrutura proposta é utilizar perguntas binárias (sim ou não) para cada um dos fatores capazes de caracterizar um trabalho precário e aplicá-las a uma amostra de empreendedoras sediadas no estado de São Paulo.

Em uma dada amostra, cada fator apresenta um percentual de respostas positivas e negativas. A média desses fatores pode também compor um índice global de precarização (IGP). Por exemplo, ao aplicar o questionário a um conjunto de empreendedoras, se o resultado das médias de respostas afirmativas para cada fator for superior a $72 \%$ (IGP), pressupõe-se que o trabalho dessa amostra seja nitidamente precário.

Assim, além de responder afirmativamente à questão 1 (Q1) deste trabalho, também foi viável a proposição de uma Zona de Precarização para a pesquisa realizada.

VASCONCELLOS, L. H. R.; DELBONI, D. P. Empreendedorismo e precarização do trabalho: o desenvolvimento e a aplicação de uma estrutura para análise de empresárias no estado de São Paulo. Revista de Empreendedorismo e Gestão de Pequenas Empresas, v. 4, n. 1, 2015. 
Para responder completamente à questão 2 (Q2) do trabalho, isto é, se seria possível criar um índice capaz de medir diferentes níveis de precarização para diferentes tipos de empreendedoras, os dados foram analisados caso a caso. Duas empresas chamaram a atenção em particular dos pesquisadores, uma na área de assessoria de imprensa de mídias sociais e outra produtora de brindes e lembrancinhas personalizadas. Enquanto a primeira não possui nenhum dos fatores de trabalho precário propostos nesta pesquisa, a segunda os possui em sua totalidade.

A figura 3 responde a essa pergunta, demonstrando que há diferenças nesse índice para diferentes empreendedoras, ainda que o porte das empresas seja similar.

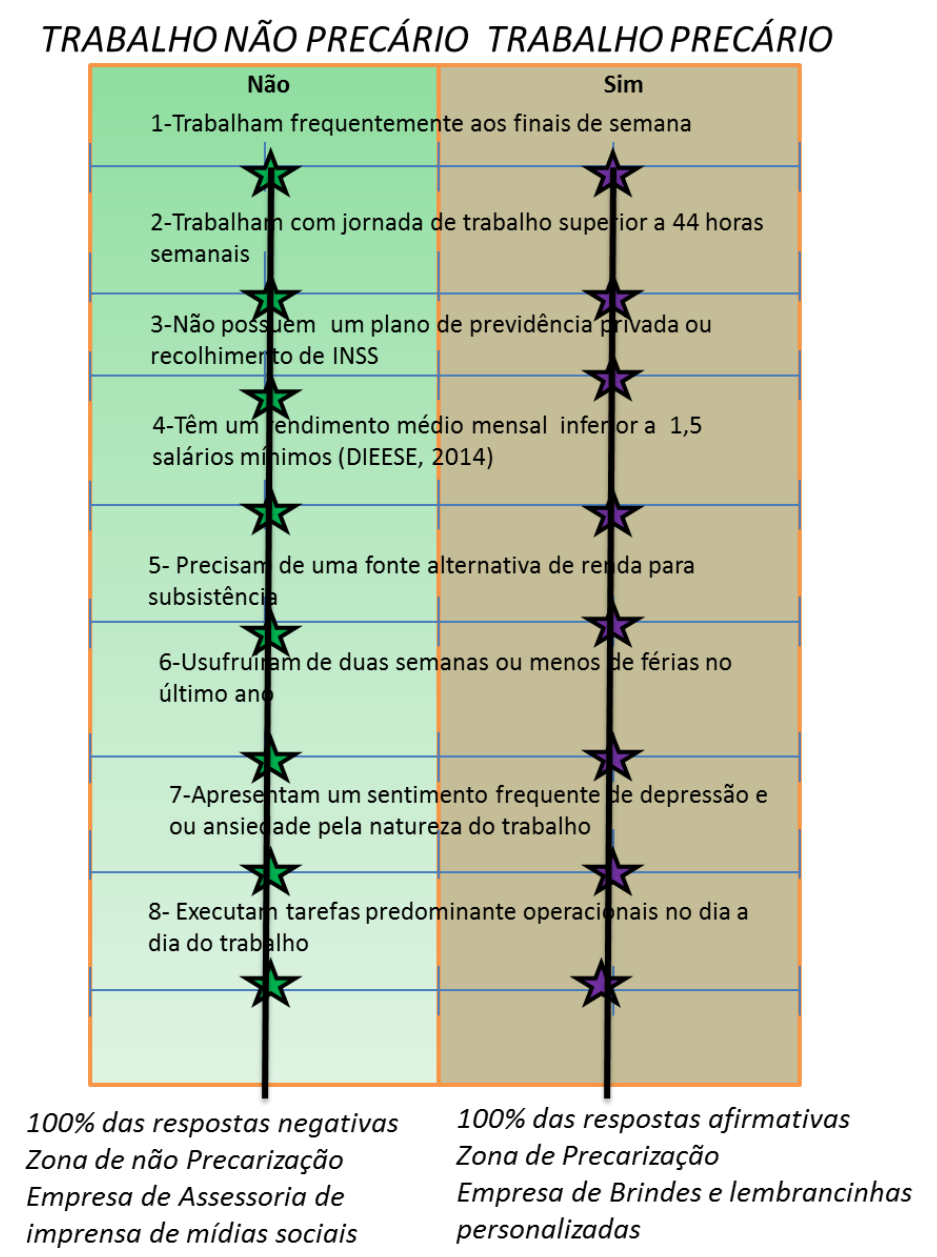

FIGURA 3 - Diferenças entre a precarização de diferentes empresas Fonte: Elaborado pelos autores (2015)

VASCONCELLOS, L. H. R.; DELBONI, D. P. Empreendedorismo e precarização do trabalho: o desenvolvimento e a aplicação de uma estrutura para análise de empresárias no estado de São Paulo. Revista de Empreendedorismo e Gestão de Pequenas Empresas, v. 4, n. 1, 2015. 
A figura 3 também apresenta dois casos extremos. Enquanto no primeiro caso não há a presença de nenhum fator caracterizador de trabalho precário, isto é, a empreendedora não trabalha frequentemente aos finais de semana; não possui uma jornada de trabalho superior a 44 horas semanais; tem um plano de aposentadoria privado; tem um rendimento médio mensal superior a 1,5 salários mínimos (DIEESE, 2014); não precisa de uma fonte de renda alternativa para subsistência; teve mais de duas semanas de férias no último ano; não apresenta qualquer sentimento frequente de depressão e/ou ansiedade em decorrência do trabalho; e não executa tarefas predominantemente operacionais no dia a dia do trabalho. No segundo caso, há a antítese desse resultado, isto é, a presença simultânea de todos os fatores que caracterizaram um trabalho precário.

É importante apontar que para as questões 1 e 2 (Q1 e Q2), de caráter mais exploratório, não serão formuladas hipóteses a priori. Como se pode constatar, suas respostas acabaram decorrendo muito mais da articulação de várias fontes utilizadas no levantamento bibliográfico e da exemplificação de duas empresas opostas na amostra pesquisada.

Uma vez definidas as questões de pesquisa, o próximo passo consistiu na formulação das hipóteses que poderiam responder às questões propostas e que serviram para orientar as etapas subsequentes do projeto de pesquisa (LEEDY, 2000).

Segundo Forza (2002), as hipóteses estabelecem relações lógicas entre duas ou mais variáveis, sendo descritas como afirmações que podem ser testadas. Para a terceira (Q3) e quarta questões (Q4) foram, respectivamente, formuladas as seguintes hipóteses:

- H1: Há indícios de precarização no trabalho de empreendedoras (possivelmente a maioria das respostas deverá estar situada na zona de precarização).

- H2: O índice global de precarização de empreendedoras por oportunidade é diferente das empreendedoras por necessidade.

VASCONCELLOS, L. H. R.; DELBONI, D. P. Empreendedorismo e precarização do trabalho: o desenvolvimento e a aplicação de uma estrutura para análise de empresárias no estado de São Paulo. Revista de Empreendedorismo e Gestão de Pequenas Empresas, v. 4, n. 1, 2015. 
Definidas as questões de pesquisa e as hipóteses a serem testadas, discutese 0 método de pesquisa que neste estudo seguiu, em linhas gerais, os passos propostos por Forza (2002), conforme figura 4, a seguir.
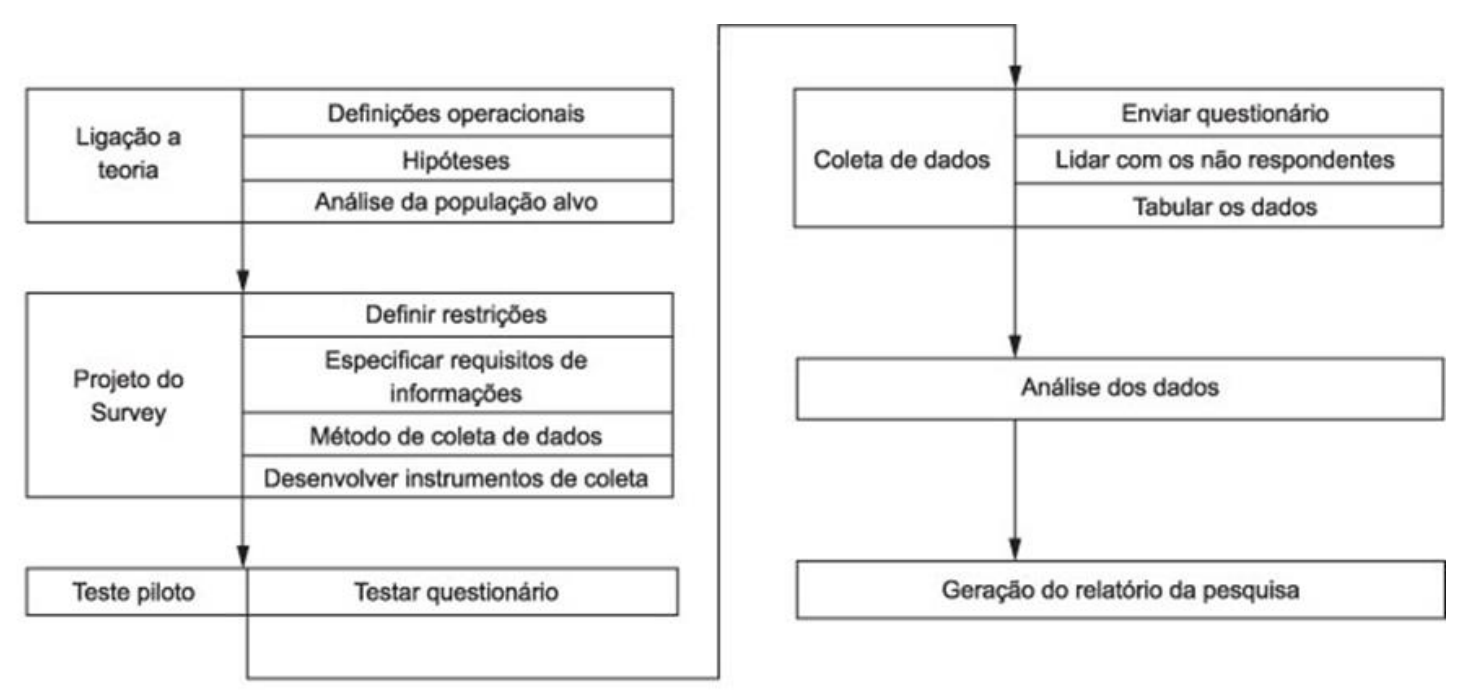

FIGURA 4 - Etapas de estruturação de uma survey Fonte: Adaptado de Forza (2002)

Definidos os objetivos e dados a serem coletados, o próximo passo consistiu no desenvolvimento do instrumento de coleta de dados. Baseado em Leedy (2000), utilizou-se um guia para a validação do questionário para relacionar as perguntas da coleta de dados com as questões de pesquisa e identificar qual o melhor tipo de pergunta.

Após sua elaboração, o questionário foi validado para duas empreendedoras contatadas previamente. Foram efetuados três ajustes de interpretação sugeridos por elas e adicionadas outras questões não desenhadas inicialmente.

O questionário foi composto, então, por 22 questões. Após a conclusão da sua versão final, o questionário foi transposto para o software "survey-monkey". Solicitou-se o apoio da FGV (Fundação Getúlio Vargas) para encaminhar o link do questionário às respondentes, por meio de sua mala direta.

A coleta de dados foi realizada via internet. Foi enviado um e-mail convite pela FGV às ex-alunas do programa "10.000 Mulheres" para a participação na pesquisa, contendo um link para o questionário. A pesquisa foi veiculada durante

VASCONCELLOS, L. H. R.; DELBONI, D. P. Empreendedorismo e precarização do trabalho: o desenvolvimento e a aplicação de uma estrutura para análise de empresárias no estado de São Paulo. Revista de Empreendedorismo e Gestão de Pequenas Empresas, v. 4, n. 1, 2015. 
dois meses, tendo resultado em 110 questionários preenchidos corretamente (de um total de 320 e-mails enviados).

\section{Caracterização das organizações}

As organizações empresariais foram caracterizadas, dentre outros aspectos, por tipo de produto ou serviço oferecido, número de empregados, tempo de existência da empresa e nível de escolaridade das empreendedoras, conforme mostra a figura 5 a seguir:

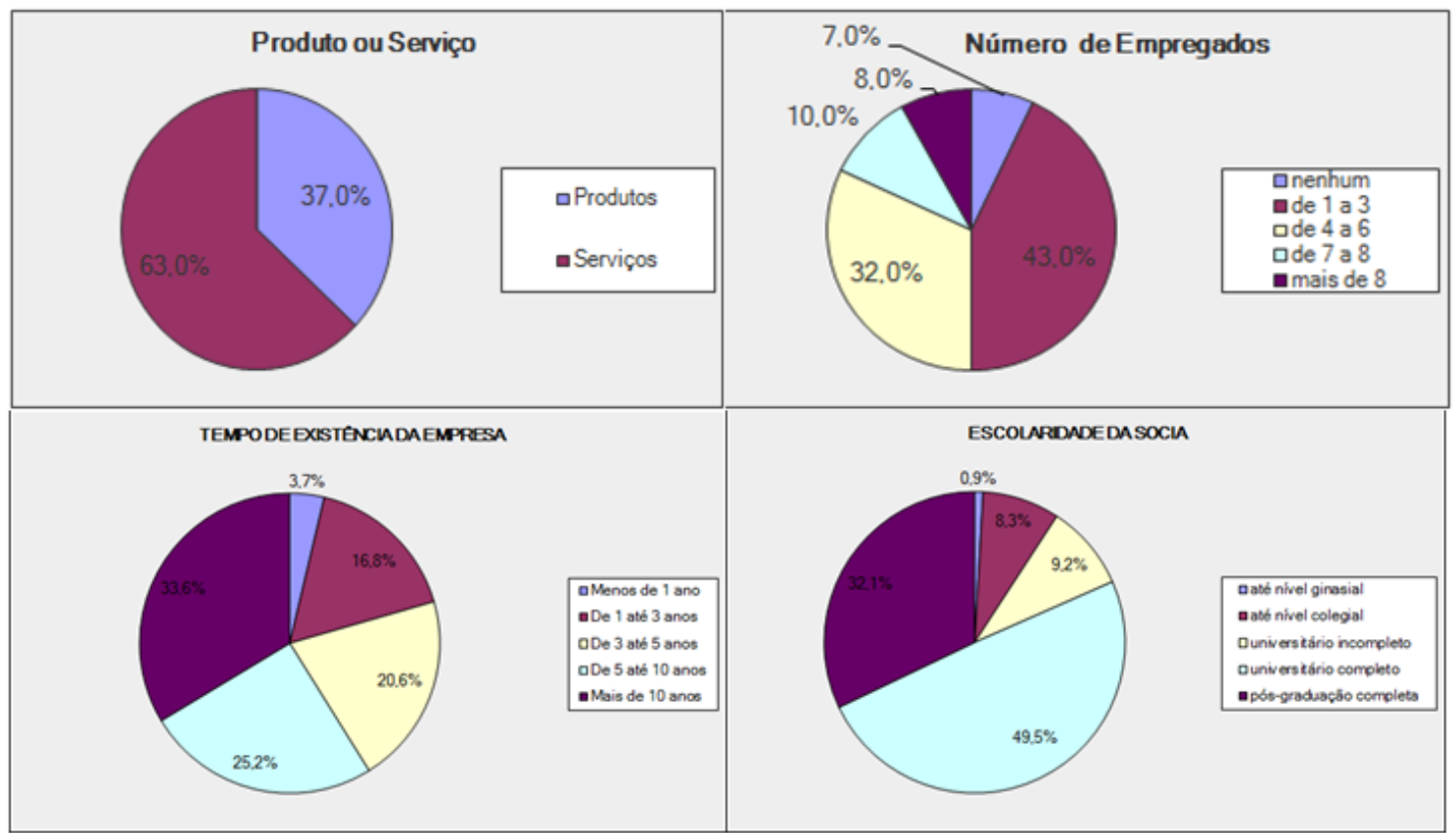

FIGURA 5 - Caracterização das empresas Estudadas

Fonte: Elaborado pelos autores (2015)

Constatou-se que 63 \% são empreendimentos do setor de serviços, $82 \%$ têm menos de oito funcionários, $58,8 \%$ das empresas atuam há mais de cinco anos no mercado e $81,6 \%$ das empreendedoras pesquisadas possui, no mínimo, o nível universitário completo.

VASCONCELLOS, L. H. R.; DELBONI, D. P. Empreendedorismo e precarização do trabalho: o desenvolvimento e a aplicação de uma estrutura para análise de empresárias no estado de São Paulo. Revista de Empreendedorismo e Gestão de Pequenas Empresas, v. 4, n. 1, 2015. 


\section{Análise e discussão dos resultados}

A questão três (Q3) do presente trabalho trata do trabalho das empreendedoras pode ser caracterizado como precário?

Para respondê-la, os pesquisadores utilizaram a estrutura referente à zona de precarização do trabalho descrita na figura 3. O resultado para a amostra pesquisada foi um IGP (Índice Global de Precarização) de 60 \%, conforme apresentado na figura 6:

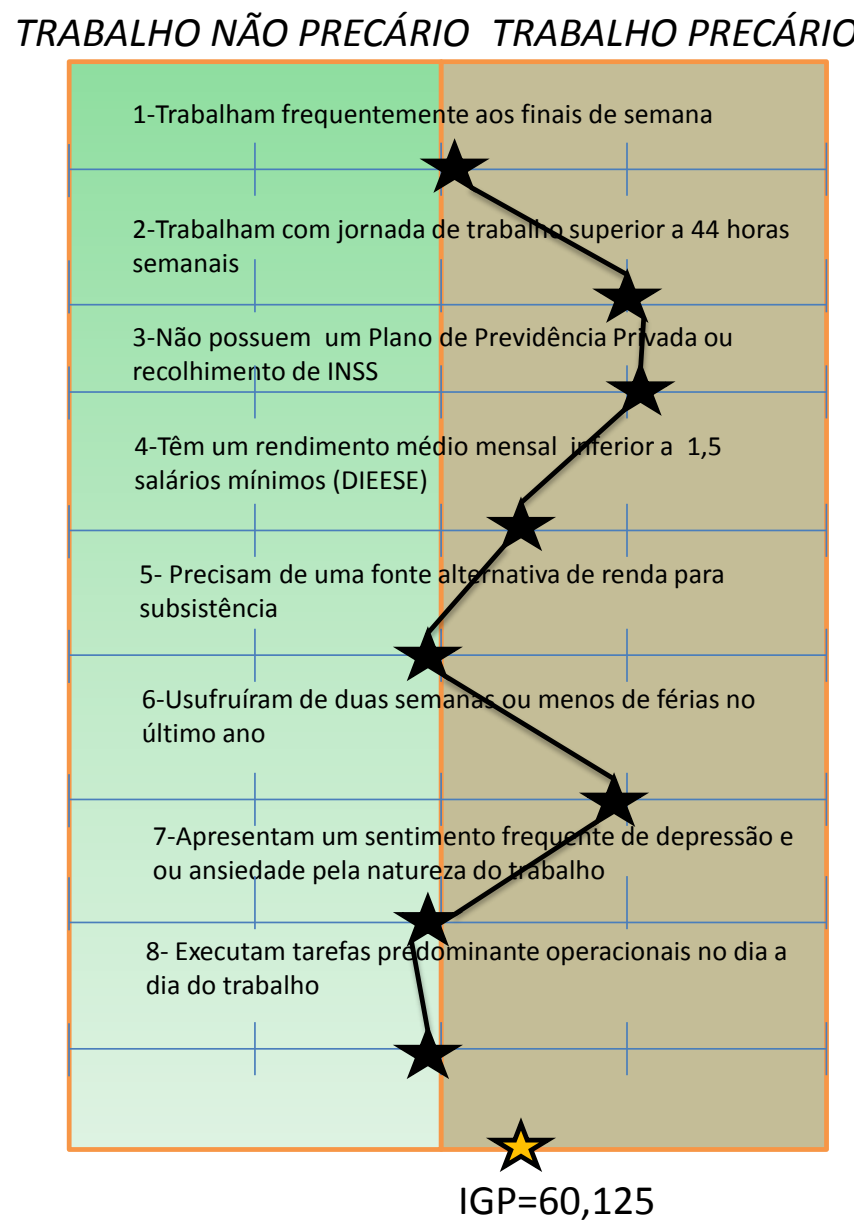

FIGURA 6 - Aplicação da estrutura proposta na amostra de empreendedoras Fonte: Elaborado pelos autores (2015)

A hipótese a ser testada para a Q3 é:

VASCONCELLOS, L. H. R.; DELBONI, D. P. Empreendedorismo e precarização do trabalho: o desenvolvimento e a aplicação de uma estrutura para análise de empresárias no estado de São Paulo. Revista de Empreendedorismo e Gestão de Pequenas Empresas, v. 4, n. 1, 2015. 
- (H1) Há indícios de precarização no trabalho de empreendedoras (possivelmente a maioria das respostas deverá estar situada na zona de precarização).

Pelos dados coletados, constata-se que, para as 110 empreendedoras analisadas, o IGP foi de aproximadamente $60 \%$. Cinco dos oito fatores propostos estão situados na zona de precarização. Portanto, há indícios de precarização, mas eles não podem ser considerados fortíssimos, pois alguns elementos estão muito próximos da zona limite (50\%). A Tabela 4 apresenta esse indicador, bem como os indicadores individuais:

\begin{tabular}{|c|c|c|c|c|c|c|c|c|c|}
\hline $\begin{array}{l}\text { Elemento de } \\
\text { trabalho } \\
\text { precário }\end{array}$ & 1 & 2 & 3 & 4 & 5 & 6 & 7 & 8 & IGP \\
\hline $\begin{array}{l}\% \text { Respostas } \\
\text { afirmativas }\end{array}$ & 53 & 75 & 78 & 61 & 47 & 72 & 48 & 47 & 60,125 \\
\hline
\end{tabular}

Analisando-se os fatores de precarização isoladamente, três números chamaram a atenção dos pesquisadores, pois representam mais de $70 \%$ de respostas afirmativas: a jornada de trabalho superior a 44 horas semanais, a ausência de um plano de previdência privada ou recolhimento de INSS e o período de férias inferior a duas semanas no último ano. Se esses dados tivessem sido indicados sozinhos, como fatores de precarização, o IGP obtido passaria para 75\%, o que poderia ser considerado um forte indício de precarização.

No que diz respeito à questão 4 (Q4); que trata dos índices de precarização do trabalho que podem ser diferentes quando comparadas às empreendedoras por oportunidade e às empreendedoras por necessidade,; um cuidado especial teve que ser observado pelos pesquisadores. A caracterização do empreendedorismo por oportunidade derivou da definição proposta pelo SEBRAE (2005): "o conjunto de indivíduos motivados pela percepção de um nicho de mercado potencial, por um sentimento de responsabilidade pela geração de emprego e desenvolvimento industrial no país; e que desejam investir em um negócio próprio".

VASCONCELLOS, L. H. R.; DELBONI, D. P. Empreendedorismo e precarização do trabalho: o desenvolvimento e a aplicação de uma estrutura para análise de empresárias no estado de São Paulo. Revista de Empreendedorismo e Gestão de Pequenas Empresas, v. 4, n. 1, 2015. 
Dessa forma, na questão 17 do questionário aplicado nesta pesquisa, a respondente deveria optar por uma das alternativas propostas, conforme tabela 2 :

TABELA 2: Alternativas para identificar empreendedorismo por oportunidade Resolvi ser empresária principalmente por (assinale apenas a principal motivaçāo):

Answer Options

Fui demitida de meu emprego anterior e não consegui outro emprego

Familiares/amigos me convidaram para entrar no negócio

Pedi demissão de meu trabalho anterior para ter mais tempo livre com minha família

Possibilidade de investir num produto/serviço inovador no mercado

Complemento de renda de meu trabalho/emprego

Outro (especifique)

\section{Response Response \\ Percent Count}

$4.8 \% \quad 4$

$48.2 \%$

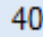

$10.8 \%$

$30.1 \%$

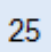

$6.0 \%$ 5

answered question skipped question
83

27

Fonte: Elaborada pelos autores (2015)

Para evitar que a própria respondente considerasse seu negócio como empreendedorismo por oportunidade (mesmo que esta não fosse a situação), os pesquisadores optaram pela estratificação apenas para as respondentes que relataram que a principal motivação para a abertura do negócio foi a possibilidade de investir em um produto/serviço inovador no mercado. Esse corte limitou a amostra em 25 respondentes.

A hipótese a ser testada foi:

H2: O índice global de precarização de empreendedoras por oportunidade é diferente das empreendedoras por necessidade.

Para a surpresa dos pesquisadores, constatou-se que o cálculo do IGP foi praticamente o mesmo, isto é 60\%, tanto para empreendedoras por oportunidade quanto para empreendedoras por necessidade, sendo refutada, portanto, a segunda hipótese. Mais ainda, constatou-se que alguns fatores de precarização são muito mais presentes entre as empreendedoras por oportunidade. É o caso da jornada de

VASCONCELLOS, L. H. R.; DELBONI, D. P. Empreendedorismo e precarização do trabalho: o desenvolvimento e a aplicação de uma estrutura para análise de empresárias no estado de São Paulo. Revista de Empreendedorismo e Gestão de Pequenas Empresas, v. 4, n. 1, 2015. 
trabalho excessiva, do rendimento médio mensal e do menor tempo para o gozo de férias (conforme mostram os números em vermelho da tabela 3 ).

TABELA 3: Comparação do IGP para empreendedoras por oportunidade e as demais EMPREENDEDORISMO POR OPORTUNIDADE $(\mathrm{n}=25)$

\begin{tabular}{l|c|c|}
\hline Fatores para caracterização de Trabalho Precário & $\%$ Sim & $\%$ Não \\
\hline a) Jornada de trabalho superior a 44 horas semanais; & 0,84 & 0,16 \\
\hline b) Trabalho frequente aos finais de semana; & 0,44 & 0,56 \\
\hline $\begin{array}{l}\text { c) Rendimento médio mensal inferior ao mínimo } \\
\text { necessário para o sustento de uma família ; }\end{array}$ & 0,80 & 0,2 \\
\hline d) Duas semanas ou menos de férias no último ano & 0,92 & 0,08 \\
\hline $\begin{array}{l}\text { e) Execução de tarefas predominantemente operacionais } \\
\text { no dia a dia do trabalho; }\end{array}$ & 0,44 & 0,56 \\
\hline $\begin{array}{l}\text { f) Sentimento freqüente de depressão e ansiedade pela } \\
\text { natureza do trabalho; }\end{array}$ & 0,48 & 0,52 \\
\hline $\begin{array}{l}\text { g) Necessidade de uma fonte alternativa de renda para a } \\
\text { subsistência; }\end{array}$ & 0,36 & 0,64 \\
\hline $\begin{array}{l}\text { h) Ausência de um Plano de Previdência Privada ou } \\
\text { contribuição para o INSS. }\end{array}$ & 0,68 & 0,32 \\
\hline
\end{tabular}
Geral $(n=110)$

\begin{tabular}{|l|l}
\hline IGP & 0,62
\end{tabular}

\begin{tabular}{|c|c|}
\hline$\% \operatorname{Sim}$ & $\%$ Não \\
\hline 0,75 & 0,25 \\
\hline 0,53 & 0,47 \\
\hline 0,61 & 0,39 \\
\hline 0,72 & 0,28 \\
\hline 0,47 & 0,53 \\
\hline 0,48 & 0,52 \\
\hline & \\
0,47 & 0,53 \\
\hline & \\
0,78 & 0,22 \\
\hline
\end{tabular}

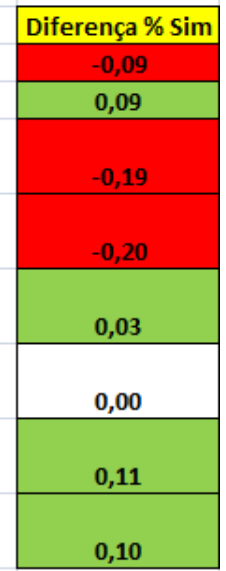

Fonte: Elaborada pelos autores (2015)

\section{Considerações finais e direções para futuros trabalhos}

Muito se tem falado sobre a questão do trabalho precário no mundo, mas sempre com os olhares voltados apenas para os empregados. São raros os estudos que voltam seu foco para a possibilidade de precarização entre empreendedores, sobretudo aqueles à frente de pequenos negócios. Parece haver certo tabu na sinalização de que o empreendedorismo pode aumentar as chances de um trabalho nitidamente precário.

Mais do que apenas detectar a existência ou não de precariedade na rotina de trabalho de empreendedoras do estado de São Paulo, por meio do presente estudo, fez-se a proposta de uma estrutura capaz de indicar, inclusive, o grau de precariedade a partir de oito fatores levantados pelos pesquisadores e mencionados reiteradamente pelos diversos autores trazidos no corpo do referencial teórico.

Por meio da estrutura criada, constatou-se que as empreendedoras pesquisadas são sim vítimas de um trabalho precário, sendo igual a 60\% ० IGP

VASCONCELLOS, L. H. R.; DELBONI, D. P. Empreendedorismo e precarização do trabalho: o desenvolvimento e a aplicação de uma estrutura para análise de empresárias no estado de São Paulo. Revista de Empreendedorismo e Gestão de Pequenas Empresas, v. 4, n. 1, 2015. 
(Índice Geral de Precarização) obtido, tanto para negócios criados por oportunidade quanto para os criados por necessidade.

Entretanto, ao contrário de que se imaginava, não é possível afirmar que exista uma relação direta entre empreendedorismo por necessidade e precariedade do trabalho. Causou surpresa a descoberta de que os fatores relacionados ao excesso de jornada de trabalho, a remuneração e o pouco tempo para férias estavam em maior medida presentes justamente entre as empresárias por oportunidade.

Deste modo, há uma contradição aparente entre os resultados desta pesquisa e a teoria entre Holzman (2006), que imputa justamente ao empregador por necessidade o convívio maior com uma rotina distante do que se pode considerar um trabalho decente.

É bem verdade que a utilização de apenas oito fatores no modelo proposto pode ser um fator limitante para a apuração dos resultados, o que sugere que, em estudos futuros, haja uma ampliação deste número, inclusive com a adoção de outros fatores relacionados a novas formas de trabalho nas sociedades modernas, o que estimularia a proposição de um novo modelo capaz de auferir mais detalhadamente quanto uma rotina pode distanciar-se de um trabalho decente.

É claro que, devido à amostra utilizada, o estudo também apresenta limitações, na medida em que foram pesquisadas apenas empreendedoras mulheres na região de São Paulo. Fica, portanto, aberta a possibilidade de realização de novas pesquisas que não façam limitação quanto a gênero e que incluam em seu objetivo, a diferenciação do grau de precariedade entre diferentes setores econômicos, o tempo de existência dos negócios, locais de funcionamento das empresas ou mesmo quantidade de empregados. Assim, há uma avenida pavimentada para futuros trabalhos que abordem esses temas.

\section{Referências:}

ANTUNES, R. Dimensões da Precarização Estrutural do Trabalho. In: DRUCK, Graça e FRANCO, Tania (orgs), A perda da razão social do trabalho: Terceirização e precarização. São Paulo: Boitempo Editorial, 2007.

VASCONCELLOS, L. H. R.; DELBONI, D. P. Empreendedorismo e precarização do trabalho: o desenvolvimento e a aplicação de uma estrutura para análise de empresárias no estado de São Paulo. Revista de Empreendedorismo e Gestão de Pequenas Empresas, v. 4, n. 1, 2015. 
Os sentidos do trabalho: ensaio sobre a afirmação e a negação do trabalho. 6. ed. São Paulo: Boitempo Editorial, 2002.

BARONI, L. L. Cresce o número de mulheres empreendedoras. Universial Brasil, 2008. <http://noticias.universia.com.br/destaque/noticia/2008/04/10/422238/resce-numeromulheres-empreendedoras.html>. Acesso em: 28 jan. 2015.

BULGACOV, Y. L. M.; CAMARGO, D.; CUNHA, S. K.; MEZA, M. L.; SOUZA, R. M. B.; TOLFO, S. R. Atividade Empreendedora da Mulher Brasileira: trabalho precário ou trabalho decente?. Rev. Psicologia Argumento, Curitiba, v. 28, n. 69, p. 337349, out./dez. 2010.

CASTEL, R. As metamorfoses da questão social: Uma crônica do salario. Petropolis, Vozes, 611 p. 1998, In NEVES, M. A.; PEDROSA, C. M. Gênero, flexibilidade e precarização: o trabalho a domicílio na indústria de confecções. Sociedade e Estado, v. 22, n. 1, p. 11-34, jan./abr. 2007.

CATTANI, A. D.; HOLZMANN, L. Dicionário de trabalho e tecnologia. Porto Alegre: Ed. da UFRGS, 2006.

COLBARI, A. L. A retórica do empreendedorismo e a formação para o trabalho na sociedade brasileira. Revista Sinais, Ed. especial de lançamento, v. 1, n. 1, p. 75111, abr. 2007.

COLODETI, V. P.; LEITE, I. C. Microcrédito, empreendedorismo e trabalho informal: "porta de saída" da pobreza?. Disponível em:<http://www.secep.com.br/arquivos/Microcredito_empreendedorismo_e_trabalho _informal-porta_de_saida_da_pobreza.pdf>. Acesso em: 29 jan. 2015.

COSTA, M. S. Reestruturação produtiva, sindicatos e a flexibilização das relações de trabalho no Brasil. RAE Eletrônica, v. 2, n. 2, p. 1-16, jul./dez. 2003.

DIEESE. Cesta básica nacional: Salário mínimo nominal e necessário. Disponível em:<http://www.dieese.org.br/analisecestabasica/salarioMinimo.html>. Acesso em: 29 nov. 2014.

FINK, A. The survey handbook. Thousand Oak: Sage, 1995.

FORZA, C. Survey research in operations management: a process-based perspective. International Journal of Operations \& Production Management, v. 22, n. 2, p. 152-194, 2002.

GALEAZZI, I. Precarização do Trabalho. In: CATTANI, A. D. (org.). Dicionário Crítico sobre Trabalho e Tecnologia, 4 ed. rev. ampl. Petrópolis: Vozes; Porto Alegre: Ed. da UFRGS, p. 242-247, 2002.

VASCONCELLOS, L. H. R.; DELBONI, D. P. Empreendedorismo e precarização do trabalho: o desenvolvimento e a aplicação de uma estrutura para análise de empresárias no estado de São Paulo. Revista de Empreendedorismo e Gestão de Pequenas Empresas, v. 4, n. 1, 2015. 
GEM, Global Entrepreneurship Monitor. Empreendedorismo no Brasil: 2006. Relatório Executivo.

Disponível em:<http://www.gemconsortium.org/docs/download/446>. Acesso em: 29 jan. 2015.

GEM, Global Entrepreneurship Monitor. Empreendedorismo no Brasil: 2013. Relatório Executivo.

Disponível em:<http://www.sebrae.com.br/Sebrae/Portal\%20Sebrae/Anexos/Relatorio\%20Exec utivo\%20GEM\%202013.pdf>. Acesso em: 29 jan. 2015.

GOMEZ, C. M.; THEDIM-COSTA, S. M. F. Precarização do trabalho e desproteção social: desafios para a saúde coletiva. Ciência e saúde coletiva, v. 4, n. 2, p. 411421, 1999.

HIRATA, H.; PRETECEILLE, E. Trabalho, Exclusão e Precarização Socioeconômica: o debate das ciências sociais na França. Caderno CRH, Salvador, n. 37, p. 47-80, jul./dez. 2002.

HOLZMAN, L. A. Dimensão do trabalho precário no Brasil no início do século XXI. In: PICCININI, V.; HOLZMAN, L.; KOVÁSCZ, I.; GUIMARÃES, V. N. (Org.). O mosaico do trabalho na sociedade contemporânea: Persistências e inovações. Porto Alegre: Ed. da UFRGS, 2006.

IBGE, Instituto Brasileiro de Geografia e Estatística. Síntese de Indicadores Sociais: Uma análise das condições de vida da população brasileira 2013. Estudos e Pesquisas, caderno n. 32. Disponível em: <ftp://ftp.ibge.gov.br/Indicadores_Sociais/Sintese_de_Indicadores_Sociais_2013/SIS 2013.pdf>. Acesso em: 29 jan. 2015.

KREMER, A.; FARIA, J. H. Reestruturação produtiva e precarização do trabalho: o mundo do trabalho em transformação. Revista de Administração - RAUSP, v. 40, n. 3, p. 266-279, jul./set. 2005.

LEEDY, P. D. Practical research: planning and design. 7th ed. Nova Jersey: Prentice-Hall, 2000.

LEME, M. C. Precariedade e Precarização do Mercado de Trabalho Brasileiro. Disponível em: <http://gvpesquisa.fgv.br/sites/gvpesquisa.fgv.br/files/publicacoes/P00131_1.pdf>. Acesso em: 29 jan. 2015.

LINDO, M. R.; CARDOSO, P. M.; RODRIGUES, M. E.; WETZEL, V. Vida pessoal e vida profissional: os desafios de equilíbrio para mulheres empreendedoras do Rio de Janeiro. Revista de Administração Contemporânea RAC, v. 1, n. 1, p. 1-15, jan./abr. 2007.

VASCONCELLOS, L. H. R.; DELBONI, D. P. Empreendedorismo e precarização do trabalho: o desenvolvimento e a aplicação de uma estrutura para análise de empresárias no estado de São Paulo. Revista de Empreendedorismo e Gestão de Pequenas Empresas, v. 4, n. 1, 2015. 


\section{A Revista da ANEGEPE

MONTALI, L. Rearranjos Familiares de Inserção, Precarização do Trabalho e Empobrecimento. Revista Brasileira de Estudos Populacionais RBEP, v. 21, n. 2, p. 195-216, jul./dez. 2004.

OIT, Organização Internacional do Trabalho. Trabalho Decente nas Américas: Uma agenda hemisférica entre 2006-2015. Informe do diretor geral. XVI reunião regional americana.

Disponível em: http://www.oitbrasil.org.br/sites/default/files/topic/decent_work/doc/agenda_hemisferi ca_537.pdf>. Acesso em: 29 jan. 2015.

PAMPLONA, J. B. Erguendo-se pelos próprios cabelos: auto-emprego e reestruturação produtiva. São Paulo: Germinal/FAPESP, 2001.

SEBRAE. GEM, Global Entepreneurship Monitor: Empreendedorismo no Brasil. 2004. Sumário Executivo. Disponível em: <http://www.dce.sebrae.com.br/bte/bte.nsf/1EC939C7F8E5D50503256FE200487D4 A/\$File/NT000A6806.pdf>. Acesso em: 29 jan. 2015.

SEBRAE. GEM, Global Entepreneurship Monitor: 2005 Empreendedorismo no Brasil. Relatório Executivo. Disponível em: <http://www.comicro.org.br/imgs/estudos/9-GEM-Empreendedorismo-noBrasil_2005.pdf>. Acesso em: 29 jan. 2015.

SOUZA, C. F. Competência empreendedora dos gestores de negócios de moda. In: ENANPAD, XXIX, 2005, Brasília. Anais... Brasília: ENANPAD, 2005. 1 CD-ROM.

TAVARES, M. A. Os fios (in)visíveis da produção capitalista. São Paulo: Ed. Cortez, 2004.

VALE, L. L. O Empreendedorismo Feminino no Espaço Produtivo do Maranhão: faces e contra-faces do trabalho feminino no atual contexto de reestruturação produtiva. In: IV Simpósio Lutas Sociais na América Latina, 2010, Londrina. Anais... Londrina: GEPAL Grupo de Políticas da América Latina, 2010, p.170-173.

VIEIRA, R. M. Precarização do Trabalho dos Executivos. GV-executivo, v. 12, n. 2, p. 76, jul./dez. 2013.

VASCONCELLOS, L. H. R.; DELBONI, D. P. Empreendedorismo e precarização do trabalho: o desenvolvimento e a aplicação de uma estrutura para análise de empresárias no estado de São Paulo. Revista de Empreendedorismo e Gestão de Pequenas Empresas, v. 4, n. 1, 2015. 